\title{
Perineal nodular swelling in a recreational cyclist
}

\author{
Stefaan Van de Perre • Filip M. Vanhoenacker • \\ Luc Vanstraelen • Jan Gaens • Maarten Michiels
}

Published online: 16 June 2009

(C) ISS 2009

\section{History}

A 41-year-old recreational cyclist was referred to our department for an ultrasound examination, because of a nodular swelling in the right perineal region, which he had

felt for several weeks. The lesion was painful on palpation, but the overlying skin was normal (Fig. 1). The patient was referred for ultrasound (Fig. 2) and MRI of the perineum (Fig. 3).

The diagnosis can be found at doi: 10.1007/s00256-009-0731-9

S. Van de Perre $\cdot$ L. Vanstraelen

Department of Radiology, Heilig Hartziekenhuis,

Gasthuisstraat 1,

2400 Mol, Belgium

F. M. Vanhoenacker $(\bowtie)$

Department of Radiology, University Hospital Antwerp,

Wilrijkstraat 10 ,

2650 Edegem, Belgium

e-mail: filip.vanhoenacker@telenet.be

J. Gaens

Department of Radiology,

AZ St.-Dimpna J.B. Stessenslaan 2,

2440 Geel, Belgium

M. Michiels

Department of Surgery, Heilig Hartziekenhuis,

Gasthuisstraat 1,

2400 Mol, Belgium

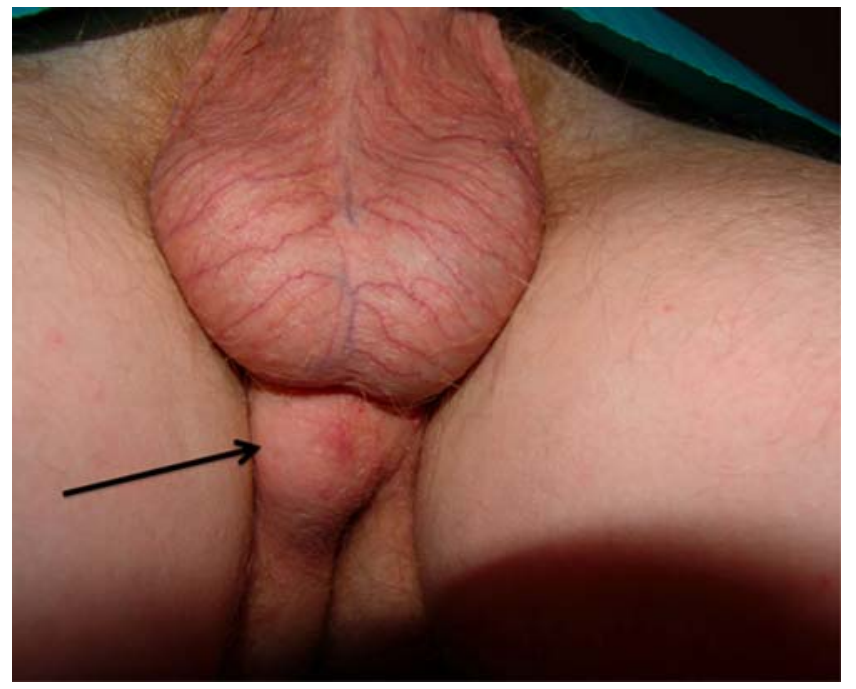

Fig. 1 Clinical picture. Nodular swelling at the right side of the perineum and posterior to the scrotal sac (black arrow). No significant abnormalities of the overlying skin 
Fig. 2 Ultrasound of the nodule with a slightly inhomogeneous echotexture (white asterisk), without marked hypervascularization at color Doppler perineal region. Note a solid
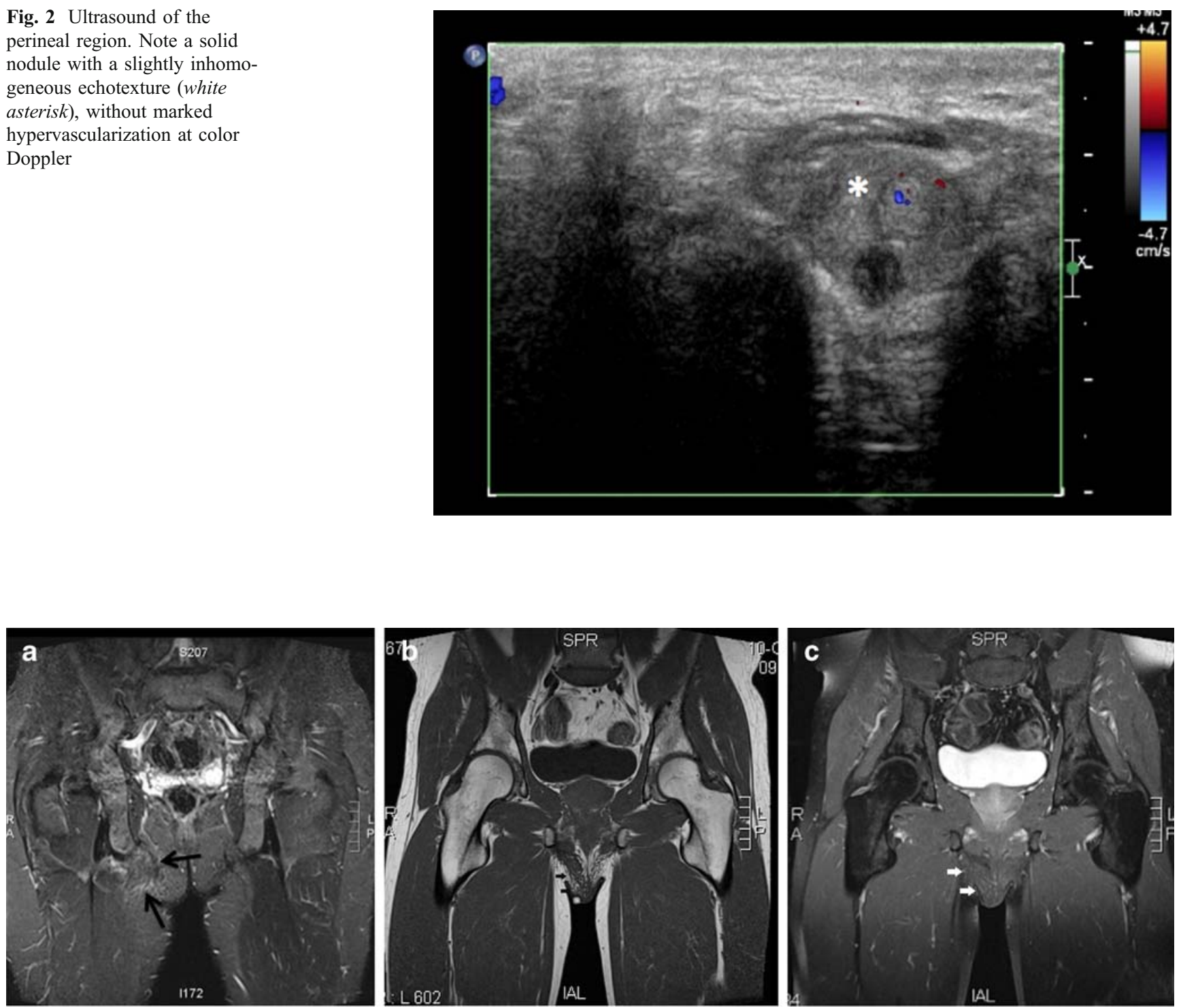

Fig. 3 MRI examination. a Coronal fat-suppressed TSE T2-weighted images (WI): Superficially located nodular lesion at the right ischial tuberosity. The nodule is of iso-intense to slightly hyperintense signal intensity, compared with muscle (black arrows). No large fluid collections or abscess formation was noted. b Coronal TSE T1-WI: ill-defined hypointense nodule within the subcutaneous fat (black arrows). c Coronal fat-suppressed TSE T1-WI after intravenous administration of gadolinium contrast: no enhancement is seen (white arrows) 